\title{
DETERMINACION DE CLORURO DE SODIO EN QUESOS ARGENTINOS
}

\author{
Minetti, M. L. ${ }^{1} ;$ Zannier, M. S. ${ }^{1} ;$ Sbodio, O. A. ${ }^{1}$ \& Tercero, E. J. ${ }^{1}$
}

\section{RESUMEN}

Se determinó el contenido de cloruros y sodio, en quesos de pasta dura, semidura y blanda de producción Argentina. Para el anàlisis de ambos iones se utilizó el método del electrodo ión selectivo, y se lo comparó con el método de la AOAC. No se observaron diferencias significativas $(\alpha \leq 0,05)$ entre los niveles de $\mathrm{ClNa}$ determinados por el método de ión selectivo y aquellos determinados por el método de la AOAC, para los quesos de media y baja humedad, pero sí se observaron diferencias significativas entre los valores hallados en los quesos de alta humedad. Los valores de ClNa encontrados por el método del ión selectivo corresponden a: $1.263,6 \pm 228,9 \mathrm{mg} / 100 \mathrm{~g}$ de queso para los quesos de pasta blanda; $1.511,8 \pm 223,5 \mathrm{mg} / 100 \mathrm{~g}$ de queso para los quesos de pasta semidura y $1.926,6 \pm 245,4$ para aquellos de pasta dura. Las concentraciones son variables y difieren de aquellos reportados por la Literatura. El método de los electrodos ión selectivo resulta aconsejable, consume escaso tiempo y no necesita oxidación previa de la muestra.

Palabras clave: queso, minerales, electrodos.

\section{SUMMARY}

\section{Content of sodium chloride of Argentine cheese}

Chloride and sodium contents were determined in hard, semihard and soft Argentine cheese by using the selective ion electrode method. Unlike low and medium moisture cheese $(\alpha \leq 0.05)$, significant differences were found when comparing sodium chloride levels obtained by this method to those of the AOAC for high moisture cheese.

Values obtained by the selective ion method were as follows: $1,263.6 \pm 228.9 \mathrm{mg} / 100 \mathrm{~g}$ for soft; $1,511.8 \pm 223.5 \mathrm{mg} / 100 \mathrm{~g}$ for semi-hard and $1,926.6 \pm 245.4 \mathrm{mg} / 100 \mathrm{~g}$ for hard cheese, respectively. Concentrations were variable and differ from those reported by Literature. The selective ion electrode method appears as highly convenient as it is less time-consuming and no previous sample oxidation is required.

Key words: cheese, minerals, electrode.

1.- Instituto de Tecnología de Alimentos. Universidad Nacional del Litoral, Facultad de Ingeniería Química, C. C. 266. (3000) Santa Fe, Argentina.

Manuscrito recibido el 11 de noviembre de 2001y aceptado para su publicación el 16 de mayo de 2002. 